\title{
ENSINO DE HISTÓRIA E O DIREITO AO PASSADO
}

\section{Margarida Maria Dias de Oliveira*}

Minhas primeiras palavras são de agradecimento ao Núcleo do PROFHISTÓRIA da UNIFAP pelos esforços empreendidos para minha vinda e todo o cuidado e carinho que me foram dispensados durante a estadia.

Gostaria de iniciar citando a escritora Chimammanda Adichie (2019) e o seu texto publicado este ano no Brasil intitulado $\mathrm{O}$ perigo de uma história única. Ela chama a atenção para o fato de que as histórias únicas de um país ou de um povo são compostas por estereótipos e que o problema deles não é que eles são inverídicos, mas que eles são incompletos. E, sobre isso, complementa:

\footnotetext{
Então, é assim que se cria uma única história: mostre um povo como uma coisa, como somente uma coisa, repetidamente, e será o que ele se tornará. É impossível falar sobre única história sem falar sobre poder. Há uma palavra, uma palavra da tribo Igbo, que eu lembro sempre que penso sobre as estruturas de poder do mundo, e a palavra é "nkali".

É um substantivo que livremente se traduz: "ser maior do que o outro". Como nossos mundos econômico e político, histórias também são definidas pelo princípio do "nkali". Como são contadas, quem as conta, quando e quantas histórias são contadas, tudo realmente depende do poder. Poder é a habilidade de não só contar a história de outra pessoa, mas de fazê-la a história definitiva daquela pessoa. O poeta palestino Mourid Barghouti escreve que se você quer destituir uma pessoa, o jeito mais simples é contar sua história, e começar com "em segundo lugar" (ADICHIE, 2019).
}

Lamentavelmente também temos histórias únicas que se relacionam ao ensino de história no Brasil. Temos a história do ensino de história contada sempre e somente a partir do Colégio Pedro II no Rio de Janeiro, da interligação como o IHGB, do suposto tradicionalismo que caracteriza o ensino de história, da sua manutenção durante quase todo o século XX, dos Estudos Sociais associados estritamente à ditadura militar e do nascimento de tudo que é novo em relação ao ensino de História, nos anos 80 do século XX.

Também temos a história única sobre a suposta superioridade da universidade em relação à escola e todos os preconceitos e distorções que isso acarreta: a ideia de que o ensino na educação básica é, somente, a simplificação da história acadêmica; a certeza que fazemos tudo correto na academia e que todos os problemas do ensino estão na escola básica e qtue o único contato possível entre universidade e escola é para a formação continuada dos professores e, sobretudo, como isso sempre é visto, atualização dos professores da educação básica.

E há, também, a história única da ideia da história geral e da história local. A primeira sempre vista a partir da visão eurocêntrica e a segunda sempre como reflexo da primeira. Ou os contrapontos história nacional e história local, sendo que local é tudo que não é feito no Rio de Janeiro ou São Paulo.

É preciso rever tudo isso, eu assim considero. Há um tempo se difundiu muito a ideia de que não seria possível mudar o mundo como defendiam as grandes utopias dos séculos XIX ou

${ }^{1}$ Conferência realizada no II Encontro de Ensino de História - ProfHistoria Unifap em dezembro de 2019.

* Doutora em História pela Universidade Federal de Pernambuco. Atualmente é professora do Departamento de História da Universidade Federal do Rio Grande do Norte. E-mail: margaridahistoria@yahoo.com.br. ORCID: https://orcid.org/0000-0002-8542-4173. 
XX, então, que deveríamos mudar nosso local de atuação ou, pelo menos, aspectos dele.

Muito bem. Estou partindo desse princípio e defendendo que para além da escrita crítica da história possamos contribuir para rediscutir os poderes que engendram essas histórias únicas e nos perguntar se estamos dispostos a tentar ou, pelo menos, reduzi-los.

Por isso, convido-os a pensar comigo se são possíveis alguns exercícios.

O primeiro desses exercícios seria com os meus colegas das universidades. Seria possível nas suas disciplinas, plenamente consolidadas (História Antiga, Brasil Colônia e similares) dar a conhecer quantos dos conteúdos que estudamos nasceram por conta da escola e/ou por demanda da sociedade? Textos da antiguidade que só foram preservados porque foram utilizados para e na escola; periodização do ensino de história do Brasil que surge com a escrita dos livros didáticos; inserção de temas/conteúdos (como pré-história) que ganharam força por conta de filmes de grande sucesso; a lei de 2003 que nascida dos movimentos sociais cria todo um corpo de especialistas, disciplinas e campo de pesquisa no Brasil, entre tantos outros exemplos?

O segundo exercício seria outra perspectiva em relação ao que, convencionalmente, se chamou história local. Toda história é local. Toda história é um recorte espaço-temporal realizada pelos profissionais de história, sejam nas suas pesquisas, sejam nas salas de aulas, sejam nos museus, nos vídeos propagados na rede mundial de computadores, no cinema, entre outras formas de divulgação do conhecimento histórico.

Os problemas que as sociedades têm a resolver são muito similares: como sobreviver (desde condições básicas de alimentação e água passando pelas relações de poder e, até, de lidar com as diversas formas de expressão seja estética ou religiosa). Ou seja, formas de sentir, pensar e agir. As respostas a essas demandas é que foram diferentes (algumas vezes), outras vezes parecidas, mas de uma forma ou de outra, construíram a diversidade e a pluralidade maravilhosas que caracterizam as experiências humanas no tempo.

Se fizermos esse exercício poderemos tratar essas experiências não como superiores ou inferiores, apenas como diferentes, e refletir sobre elas a partir do espaço que vivenciamos.

Os convido a um terceiro exercício que é trabalhar com a imensidão de dados produzidos sobre acontecimentos, personagens, fenômenos em nossos espaços de atuação, sejam sítios, escolas, comunidades quilombolas, comunidades indígenas, cidades, muitos dos quais já apropriados pelas universidades - sejam nas pesquisas e produção de materiais do PIBID, Profhistória, Grupos de Pesquisas, Programas de Pós-graduações acadêmicos - para produzirmos materiais sistematizados e registros sistemáticos das nossas experiências de ensino-aprendizagem - que possibilitem dialogar com as experiências do mundo, a partir da nossa perspectiva.

Vou lhes mostrar um só exemplo do que eu e a Profa. Juliana Souza, docente como eu na UFRN, produzimos junto com os nossos alunos da graduação durante os anos de 2017 e 2018 . O Departamento de História da UFRN tem um investimento antigo (data de mais ou menos 1988) de trabalho com acervos e, por isso, em um dos nossos laboratórios há um acervo significativo (disponível no site http://repositoriolabim.cchla.ufrn.br/) da Comarca de São José de Mipibu, cidade da área Metropolitana de Natal, responsável no período colonial pela produção açucareira da então província.

Para elaboração do material que vou citar um exemplo, nós elegemos alguns princípios que estão contidos nessa definição de produto:

Produto é um material didático acompanhado de orientações e/ou sugestões para sua utilização em atividade de ensino-aprendizagem, a partir de problema(s) diagnosticado(s) pelo 
docente e que tem como objetivo saná-lo ou contribuir para sua diminuição. Pressupõe o uso do método científico no todo ou em parte como forma de colocar o aluno no centro do processo de construção do conhecimento, associando os objetivos de aprendizagem aos de formação da cidadania e construção da autonomia do sujeito aprendente. (SOUZA, OLIVEIRA, no prelo).

Além disso, partimos da necessidade de trabalhar com temas já estudados nos livros didáticos, consolidados como conteúdos da educação básica para que o professor não se sentisse desmotivado a utilizar nosso material para "não interromper" o conteúdo que teria que ministrar.

A primeira proposta de sequência didática exposta no Catálogo que elaboramos tem como título A lei, os costumes e as diferentes concepções sobre direito de propriedade. E na sua descrição lê-se:

Professor, este material consiste numa ficha de duas faces. Na primeira há uma charge sobre disputa de terra, e no verso há alguns artigos da Lei de Terras de 1850. A proposta é articular discussões sobre escravidão, trabalho livre e direito à terra. Nesse sentido, propõe-se a realização de uma atividade em três momentos, nos quais os alunos analisarão a charge conforme o roteiro que se encontra em anexo, a fim de discutir as diferentes concepções relacionadas ao direito de posse da terra que se encontram em disputa no caso representado pela charge. Em seguida, deverão elaborar painéis temáticos para serem expostos para a turma e/ou para a escola, com base em pesquisas sobre os conflitos envolvendo a disputa pela terra no Brasil de hoje.

Procuramos com a descrição apresentar ao professor, em linhas gerais, do que trata a proposta para continuar explicitando os objetivos que são: exercitar a pesquisa e busca de informações; identificar mudanças e permanências; caracterizar ações de sujeitos diferentes, contextualizando-as num espaço-tempo determinado; compreender o conceito de justiça numa perspectiva histórica.

É importante observar que o conteúdo é meio para atividades em que os alunos são construtores dos seus conhecimentos. Isso não diminui a importância dos conteúdos, pelo contrário, mas eles não são um fim em si mesmo.

Nesse caso específico tratamos da Lei Euzébio de Queiróz e a Lei de Terras, dois assuntos tradicionalmente abordados nos livros didáticos e, por meio do material específico (charge) e as sugestões de atividades propostos tratar os conflitos gerados pelas disputas acirradas com a transformação da terra em mercadoria e a libertação da mão-de-obra, envolvendo pequenos proprietários que tinham direitos superpostos, baseados em diferentes concepções sobre a propriedade da terra.

Como estratégias para execução da atividade em sala de aula sugerimos - por meio de apresentação minuciosa - tarefas que incluíam a interpretação da charge e de outros materiais como gráficos e tabelas; a busca e apropriação das informações das leis referenciadas e seu contexto; a construção de narrativas pelos alunos por meio de painéis; elementos da atualidade sobre a disputa pela terra para perceber essa discussão na longa duração e, para isso, o acesso a meios de comunicação; o estímulo e aprendizado do trabalho coletivo e a comunicação dos saberes construídos para toda a comunidade escolar.

Voltando a convocação de Chimamanda Adichie o que eu queria ressaltar com esta minha fala hoje é que inverter perspectivas não é só mais uma visão. Elas podem desconstruir muitos modelos consolidados e isso pode causar muito incômodo ou, pelo menos, retirar-nos da nossa zona de conforto.

Não é muito difícil pluralizar a história do ensino de história no Brasil. Os Liceus, Ateneus, 
grupos escolares de todos os tipos, escolas isoladas, têm sido estudados por vários colegas da história da educação e por profissionais de História que trabalham com a História da disciplina. Não estamos negando o papel do Colégio Pedro II, mas as histórias do ensino de história nas províncias, nas cidades, nessa imensidão que denominamos Brasil têm outros dados, informações, sujeitos, que devem ser trabalhados e operados para entendermos como essas tradições foram se constituindo. Portanto, temos condições sim, por meio das pesquisas já realizadas de pluralizar a história do ensino de história.

Compreender a escola como local de um saber específico que tem referência na produção acadêmica, mas que se coaduna, interage com uma série de outros saberes é libertador, principalmente, para os professores em formação que precisam saber diferenciar público e objetivos da educação básica e dos nossos cursos de graduação em história. E isso em nada tem a ver com a ideia propagada de que nas universidades só vemos teorias e nas escolas, a prática é diferente, mas entender como teoria e prática consistem em saberes diferenciados que se organizam para atender públicos e objetivos também diversos.

A principal consequência imediata disso é desconstruir a visão hierarquizada entre universidade e academia e valorizar os saberes construídos pelos professores e vê-los, por exemplo, nos mestrados profissionais como o que o nome do Programa diz - PROFISSIONAIS que vêm dialogar com outros PROFISSIONAIS.

Trabalhar a história local - pode ser a do nosso país em relação a Europa - pode nos tirar do lugar de reflexo (aconteceu lá e depois aconteceu aqui), mas sobretudo de um subproduto dessa ideia que é: "vejam somos bons, evoluídos, ou qualquer ideia do tipo, porque fizemos igual aos europeus, ou aos cariocas, ou aos paulistas ...” ou “a África também é evoluída porque teve reinos como os europeus".

Mas, também não vou enganá-los, nem dizer que tudo isso é só uma questão de boa vontade. Como Chimamanda Adichie ressaltou isso tem a ver com poder e com relações e realidades que envolvem muitas variáveis. Isso tem a ver com o acesso e a distribuição de livros no país, por exemplo. Afinal, o que é mais acessível? é eu ler um texto de um colega do eixo sul-sudeste ou eu ler um texto de um colega do Ceará ou do Mato Grosso do Sul?

Portanto, isso tem a ver com nossas bibliografias indicadas para os alunos, com quem nós citamos. Isso tem a ver com as relações de poder dentro da academia, de financiamentos, com as relações de orientação/orientador, de grupos de pesquisa, de publicações, de eventos.

Como eu afirmei antes, a questão é: até onde estamos dispostos a mudar?

Pergunto se estamos dispostos porque isso faz parte de uma decisão política, do reconhecimento que nós - profissionais de história - não ganhamos com isso. Esta é uma atitude em que todos perdem.

E precisamos construir pautas mínimas consensuais para que possamos avançar.

Dos últimos vinte e cinco anos que tenho acompanhado essas discussões como pesquisadora do ensino de história, vejo que avançamos muito, mas poderíamos ter avançado mais e, acredito, que podemos sim constituir pautas mínimas para o ensino-aprendizagem de história e acho que iniciarmos pelas nossas universidades seria um grande passo.

O mais gratificante de vir a eventos como este é que vemos os alunos da graduação iniciando suas carreiras e os colegas da Educação Básica pautando suas reflexões sobre nossos campos de atuação. Eu ficaria muito mais feliz, se nós construíssemos com uns e com outros, caminhos a seguir que fossem mais promissores de avanços mais rápidos, ou pelo menos, de não retroceder tanto. 
Conclamo-os a ir à luta, afinal, o passado, como afirma John Lewis Gaddis (2003), é o nosso único banco de dados e é dele que temos tirado informações sobre as experiências humanas no tempo. É a partir dessas informações e do que projetamos que inventamos nossos futuros possíveis e para a maioria de nós, em geral, só temos as amarras a perder.

\section{Referências}

ADICHIE, Chimamanda Ngozi. 0 perigo de uma história única. São Paulo: Companhia das Letras, 2019.

GADDIS, John Lewis. Paisagens da História: Como os historiadores mapeiam o passado. Rio de Janeiro: Campus, 2003.

SOUZA, Juliana Teixeira de; OLIVEIRA, Margarida Maria Dias de. Catálogo. I Catálogo de Materiais

Didáticos para o Ensino de História. Escravidão. RN: EDUFRN, (no prelo). 